\title{
New frontiers in gene targeting and cloning: success, application and challenges in domestic animals and human embryonic stem cells
}

\author{
Chris Denning ${ }^{1}$ and Helen Priddle ${ }^{2 *}$ \\ ${ }^{1}$ University of Nottingham, Division of Animal Physiology, School of Biosciences, Sutton Bonington LE12 \\ 5RD, UK; and ${ }^{2}$ Roslin Institute, Gene Expression and Development, Roslin, Midlothian EH25 9PS, UK
}

\begin{abstract}
Until recently, precise modification of the animal genome by gene targeting was restricted to the mouse because germline competent embryonic stem cells are not available in any other mammalian species. Nuclear transfer (NT) technology now provides an alternative route for cell-based transgenesis in domestic species, offering new opportunities in genetic modification. Livestock that produce human therapeutic proteins in their milk, have organs suitable for xenotransplantation, or that could provide resistance to diseases such as spongiform encephalopathies have been produced by NT from engineered, cultured somatic cells. However, improvements in the efficiency of somatic cell gene targeting and a greater understanding of the reprogramming events that occur during NT are required for the routine application of what is currently an inefficient process. The ability to reprogramme and genetically manipulate cells will also be crucial for full exploitation of human embryonic stem (hES) cells, which offer unparalleled opportunities in human health and biotechnology. Particularly pertinent are directed differentiation of hES lines to specific cell lineages, production of cells that evade the patient's immune system and ensuring the safety of ensuing transplants. This review will discuss some of the successes, applications and challenges facing gene targeting in livestock and hES cells.
\end{abstract}

One of the fundamental dogmas in biology is that through the processes of transcription and translation, DNA templates can be decoded to produce peptides. This two-step amplification process means that one gene can produce numerous RNA transcripts, each in turn leading to production of many peptides. Consequently, studying gene function by attempting to completely eliminate specific RNAs or proteins is challenging because of the high turnover and numbers of these molecules. By contrast, gene disruption at the DNA level by gene targeting (targeted integration by homologous recombination) is absolute and unambiguous (Capecchi, 1989). However, the precision of gene targeting is not limited simply to gene disruption. Directed insertion or substitution of genetic sequence is also possible. More subtle changes can also be made, for example promoter sequences can be altered to modulate expression or coding sequences can be mutated to study function

*Present address: Molecular Embryology and Stem Cell Laboratory, School of Human Development, Obstetrics and Gynaecology, D Floor East Block, Queens Medical Centre, Nottingham NG7 2UH, UK

Email: chris.denning@nottingham.ac.uk of individual domains. Thus, gene targeting potentially enables the genetics of virtually any organism to be altered in a precise manner (Capecchi, 1989).

Gene targeting of an endogenous gene was first reported in mice by Smithies et al. (1985). This technology has since provided tremendous insight into a plethora of biological questions in functional genomics, allowed modelling of diseases including cancer and is the major basis of the desire to extend targeting to other species. This review begins by giving a brief account of how targeted modification is achieved in mice. However, pluripotent embryonic stem (ES) cells, which have been central to success in mice, are not available in any domestic species, despite considerable efforts to isolate them. This precluded extension of the technology to livestock until the development of an alternative route for cell-based transgenesis that involved cloning by nuclear transfer (NT; Campbell et al., 1996). This issue will form the second part of the review. There are now several reports describing gene targeting in livestock (McCreath et al., 2000; Denning et al., 2001a; Dai et al., 2002; Lai et al., 2002). However, these successes mask tremendous inefficiencies. Increasing the efficiency of isolation of gene-targeted primary somatic cells and deepening the understanding of the underlying 
reprogramming events that occur during NT will be crucial for routine use of this technology. The final part of the review will consider the newly emerging field of human embryonic stem (hES) cells. The authors will speculate on the feasibility of using NT in 'therapeutic cloning' to produce blastocysts to permit isolation of patient specific hES cells. Finally, it will be proposed that whether hES cell lines are derived from blastocysts produced by NT or IVF, or by alternative methods involving direct reprogramming of somatic cells, gene targeting will play a central role in unlocking the full potential of hES cell lines for uses such as tissue transplantation and directed differentiation.

\section{Development of gene targeting in mammals}

Until ES cells were derived from mouse blastocysts, direct 'pro-nuclear injection' into the male pro-nucleus of the zygote was the only method available to modify mammals genetically. Although pro-nuclear injection is a robust technique, the random nature of integration is inefficient, often gives rise to unpredictable transgene expression and suffers from mosaicism such that the transgene is not expressed in all cells of the animal (Clark et al., 1994). The most serious limitation is that pro-nuclear injection provides no means to modify endogenous genes.

Isolation of pluripotent murine ES $(\mathrm{mES})$ cells that can contribute to all tissues of the fetus (Evans and Kaufman, 1981; Martin, 1981) provides a route for precise modification of the mouse genome by gene targeting (Capecchi, 1989). In this approach, the desired modification is introduced into a cloned copy of the chosen gene by standard recombinant DNA technology. The modification is then transferred to the genome of $\mathrm{mES}$ cells by means of homologous recombination between the exogenous modified DNA and the cognate DNA sequence in the ES-cell chromosome. Screening procedures such as PCR or Southern blot analysis are used to identify the rare ES cells in which the correct targeting event has occurred. The appropriate cell is then clonally expanded and maintained as a pure population, whereupon these cells are microinjected into the blastocoel of the preimplantation mouse embryo (Fig. 1). This blastocyst is surgically transferred to the uterus of a foster mother, where development is allowed to progress to term. The requirement is to produce a 'germline chimaera', that is, the donor ES cells contribute to a range of tissues, specifically including the germ cells. Breeding from the chimaera produces heterozygous offspring that can be interbred to produce a pure line of homozygous animals with the engineered modification (Capecchi, 1989).

As this strategy allows defined genes to be modified in a precise manner, gene targeting theoretically provides the opportunity to inactivate or alter gene activity at will. This approach has now been used to engineer mice so that a range of biological processes within the setting of the whole animal can be systematically analysed. For example, knockout mice have been used to establish potential links between female reproduction and energy homeostasis. Mice lacking insulin receptor substrate 2 (IRS-2 ${ }^{-/}$) are overtly diabetic, displaying a similar pathophysiology to that of human type II diabetes. IRS-2 ${ }^{-1-}$ mice also have small, anovulatory ovaries with reduced numbers of follicles and as a consequence are infertile (Burks et al., 2000).

Clearly targeted genetic manipulation of mice has played, and continues to play, an essential role in the understanding of functional genomics. Extension of gene targeting to other mammalian species would have a significant impact on biotechnology and also the understanding of human disease and development.

\section{The need for nuclear transfer}

In mice, gene targeting is a relatively routine procedure as ES cells can be maintained in culture for long periods and gene-targeted clones that can contribute to the germ line of chimaeras can be isolated at high efficiency (for example, see Okkenhaug et al., 2002). Given these qualities, isolation of similar pluripotential cells from livestock is likely to permit similar studies to be carried out in these species. However, despite years of effort, stable and reliable ES-cell lines that can contribute to the germ line, a step that is critical for generating engineered animals by this route, have not been isolated from any domesticated animals. For example, Piedrahita et al. (1998) isolated pluripotent primordial germ cells from pig fetuses at day 25-27 of gestation. These cells were transfected with a DNA construct and transgenic cells were isolated. Transgenic chimaeras were produced but germline transmission was not reported when injected into recipient blastocysts. Cibelli et al. (1998) adopted an alternative approach. By using bovine fetal fibroblasts as donors in nuclear transfer (see below), cloned blastocysts were produced which were used to isolate cultured ESlike cells. In the chimaeras produced from these cells, contribution was seen in several tissues but these did not include the germ cells.

The lack of suitable ES cells represented a considerable barrier to gene targeting in livestock so the discovery that animals could be cloned from somatic cells in culture by NT was met with significant excitement. Although NT had been possible for many years in sheep and cattle using embryonic blastomeres (Willasden et al., 1986; Prather et al., 1987), it was not until the landmark paper by Campbell et al. (1996) that this technique could have a significant impact on gene targeting in livestock. Campbell and co-workers demonstrated that NT could reset the developmental programme; viable offspring could be produced from cells that had been maintained in culture and expressed markers of the differentiated state. In this approach, a primary somatic cell was taken 


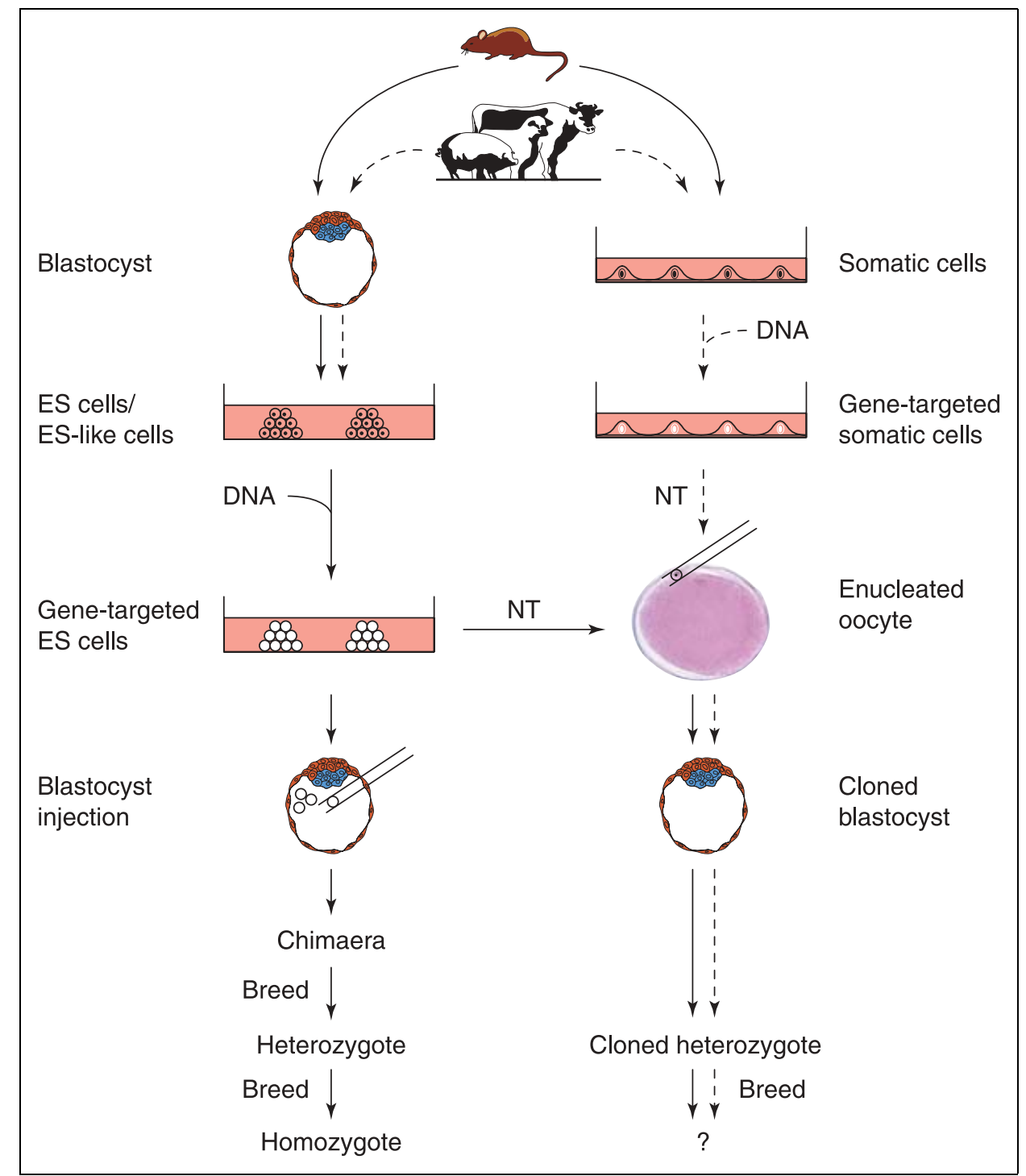

Fig. 1. Comparison of successful gene targeting strategies in mice and livestock. Steps that have been successfully reported for mice (solid arrows) or livestock (broken arrows) are indicated. Routes of transgenesis shown: left, blastocyst injection; right, nuclear transfer (NT). See text for details of these methods. Although gene targeting in mouse embryonic stem (ES) cells has been achieved, there are no similar reports for livestock. The opposite is true for somatic cells, thus generating a need for NT. Gene-targeted heterozygous mice have been produced by both blastocyst injection and NT, whereas heterozygous pigs and sheep have been produced only via NT. Although to date animals have been bred to homozygosity using only the blastocyst injection route, clones are usually fertile and so producing homozygous animals via breeding should also be possible. Alternatively, homozygosity can be achieved by isolating cells from a gene-targeted cloned animal, disrupting the second allele and then using these cells as donors for NT (for example, see Phelps et al., 2003; see text for details).

from a culture dish and injected under the zona pellucida of an enucleated metaphase II oocyte. Through electrical stimulation, the membranes of the oocyte and somatic cell were fused, while also activating the developmental programme. After culturing the embryo to the blastocyst stage, it was transferred to a surrogate mother and allowed to progress to term. Similar techniques have been successfully used to clone sheep, cows, pigs, mice, goats, rabbits and cats using a range of primary types of cell, including fibroblast, cumulus, Sertoli, gonad, neural, oviduct, uterine, granulosa, mammary, muscle, liver, testis and germ cells, which have been isolated from embryonic, fetal or adult stages of development (see Wilmut and Peterson, 2002). 
The success of the NT technique enabled precise engineering of the genome to be extended to animals other than mice (Fig. 1), providing new opportunities in biotechnology and disease modelling. Genetically engineered mice have been fundamental to assigning function to genes and there are now over 2000 published murine gene knockouts (see http://research.bmn.com/mkmd). However, these knockouts provide few realistic opportunities to develop clinical treatments, monitor development of the fetus or the developing reproductive system in the fetus and adult, or study the long-term effects on health caused by the engineered mutations. Thus, the major restrictions to modelling human pathology in mice are differences in size, lifespan, physiology and the nature of the reproductive system, including the number of progeny produced.

Sheep have already been used to investigate the effects of maternal nutrition on the resulting offspring. The long gestation period in this species has allowed exploration of the existence of discrete 'windows of sensitivity' to the programming of fetal and juvenile physiological control mechanisms following maternal undernutrition (Heasman et al., 1998). There is also evidence that sheep are superior to mice for modelling certain human diseases. For example, numerous strains of mice have been engineered with a mutation in the CFTR gene and so would ideally display the cystic fibrosis (CF) phenotype (reviewed in Harris, 1997). In humans this is primarily characterized by recurrent lung infection and pancreatic destruction. However, CF mice do not present the disease; they have normal pancreatic function and little airway disease in a limited lifespan. Instead, the majority of strains die from intestinal obstruction. By contrast, it is anticipated that sheep would provide a better model. Tissue-specific and developmental patterns of expression of the CFTR gene in sheep are very similar to those seen in humans. Furthermore, there are significant anatomical, functional and electrophysiological similarities between the lung in sheep and humans (Harris, 1997).

Modifications to livestock could also be made to influence traits such as growth rate and feed efficiency in agricultural livestock breeding. From a biotechnological standpoint, genes in livestock could be replaced with their human counterparts in order to use them as a source of the protein (reviewed in Clark et al., 2000). Models need not be restricted to farm animals; gene targeting in rabbits will be of importance to the pharmaceutical industry when, for example, cannulation of specific blood vessels is required, a technique that is technically challenging in mice (Fan et al., 1999).

Alternatively, human therapeutic proteins could be produced in the milk of domestic species by directing expression to mammary tissue. Using this approach, Schnieke et al. (1997) transfected sheep fibroblasts with a DNA construct encoding human blood-clotting factor IX and selected those with the highest expression for NT. Although the strategy was not designed specifically to target the transgene to a specific locus, it provided the first evidence that cells could be transfected and selected, while still remaining competent for NT, thus setting the stage for gene targeting in livestock.

\section{Gene targeting in livestock}

A major driving force in the development of gene targeting in livestock has been the biotechnology sector. Consequently, gene targeting has so far been directed towards commercial or medical applications. Human alpha-1-antitrypsin (hAAT) is a plasma protein that inhibits elastase, a key enzyme in the inflammatory response that can lead to excessive tissue destruction. Therefore, hAAT is a potential candidate for the treatment of CF lung disease and other conditions in which connective tissue is broken down irreversibly. McCreath et al. (2000) adopted a gene-targeting strategy to insert a transgene encoding hAAT into the $3^{\prime}$ untranslated region of the $\alpha 1$ (I) procollagen (COL1A1) locus. The design of the construct enabled high expression of hAAT in the milk of the transgenic sheep.

This gene-targeting strategy involved specific insertion of a transgene rather than deletion of endogenous coding sequence and hence gene function, which was the aim of the current authors' strategy. The production of sheep fetuses and lambs that carried targeted disruptions in one allele of either the $\operatorname{Pr} P$ gene, which encodes prion protein, or the GGTA1 gene, which encodes $\alpha(1,3)$ galactosyl transferase, was reported (Denning et al., 2001a). Prions are a novel form of infectious agent that cause spongiform encephalopathies in humans and animals (Bueler et al., 1992). As sheep and particularly cattle have functional $\operatorname{Pr} P$ genes and are used to produce biomedical products such as gelatin, collagen and, increasingly, human proteins after genetic modification, it may be appropriate to produce prion-resistant populations. Galactosyl transferase is responsible for the presentation of galactose- $\alpha(1,3)$-galactose (the gal epitope) on the extracellular surface of cells of all organisms, with the exception of catarrhines (Old World monkeys, apes and humans), which have lost the function of the GGTA1 gene (Galili et al., 1985). The difference in cell-surface epitopes is believed to be a major cause of hyperacute rejection of livestock organs xenografted to humans, and so eliminating the gal epitope could alleviate some aspects of the rejection stimulus.

Although certain tissues in a gal-knockout sheep would be useful for xenotransplantation and for assessing the extent to which this epitope is responsible for rejection, considerable efforts have been made to create similar genetic disruptions in pigs due to their close similarity in organ size and physiology to humans, and large litter size. Two independent groups (Dai et al., 2002; Lai et al., 2002) reported production of live pigs in which one allele of the GGTA1 gene had been disrupted. Importantly, Lai et al. (2002) sought 
Table 1. Efficiency of gene targeting in primary livestock fibroblasts

\begin{tabular}{|c|c|c|c|c|c|}
\hline Target gene & $\begin{array}{l}\text { Number of cells } \\
\text { transfected }\end{array}$ & $\begin{array}{l}\text { G418 resistant } \\
\text { colonies }^{\mathrm{a}}\end{array}$ & $\begin{array}{l}\text { Colonies confirmed as } \\
\text { gene targeted }^{b}\end{array}$ & $\begin{array}{l}\text { Absolute targeting } \\
\text { frequency }^{\mathrm{C}}\end{array}$ & Reference \\
\hline \multicolumn{6}{|l|}{ Sheep } \\
\hline COL1A1 & $5 \times 10^{5}$ & 70 & $46(66 \%)$ & $9 \times 10^{-5}$ & McCreath et al., 2000 \\
\hline $\operatorname{Pr} P$ & $5 \times 10^{6}$ & 533 & $5(1 \%)$ & $1 \times 10^{-6}$ & Denning et al., 2001a \\
\hline GGTA1 & $1 \times 10^{7}$ & 1445 & $25(1.7 \%)$ & $2.5 \times 10^{-6}$ & Denning et al., 2001a \\
\hline \multicolumn{6}{|l|}{ Pigs } \\
\hline GGTA1 & $4.9 \times 10^{7}$ & 159 & $8(5 \%)$ & $1.6 \times 10^{-7}$ & Lai et al., 2002 \\
\hline GGTA1 & $8 \times 10^{6}$ & 1105 & $17(1.5 \%)$ & $2.1 \times 10^{-6}$ & Dai et al., 2002 \\
\hline
\end{tabular}

${ }^{a}$ G418 drug selection allows isolation of cells that have been stably transfected with the targeting construct and are expressing the neomycin phosphotransferase drug resistance gene. Most colonies will result from random integration of the targeting vector; only some will be correctly targeted.

bParentheses indicate the ratio of confirmed gene-targeted colonies to G418 resistant colonies.

${ }^{\mathrm{c}}$ Absolute targeting frequency expresses number of targeting events on a per cell basis, demonstrating the low frequency of the targeting process.

to achieve this in a line of pigs that had long been used for xenotransplantation studies and that consistently tested negative for transmission of porcine endogenous retrovirus to human cells in vitro. Ultimately, these studies paved the way for the production of gal-knockout pigs. Phelps et al. (2003) attempted to target the disruption of the second GGTA1 allele by gene targeting and selecting for gal-negative cells with toxin $A$ from Clostridium difficile, which has a cytotoxic effect on galpositive cells. However, inactivation of the second allele did not arise by gene targeting; rather it occurred by a spontaneous $\mathrm{T}>\mathrm{G}$ transversion that was selected for by toxin A. These gal-knockout pigs should now permit a full assessment of any benefit on hyperacute rejection and the subsequent delayed rejection mechanisms.

However, these successes mask the tremendous inefficiencies of producing gene-targeted livestock. Significant demands are placed on primary somatic cells during gene targeting. The efficiency of homologous recombination in these cells compares with the lower end of the range reported for mES cells (Templeton et al., 1997). As a result, it is virtually a necessity to use promoterless-type gene-targeting strategies (Clark et al., 2000; Harrison et al., 2002), which enrich for correct targeting events by 100 - to 500 -fold, because drugresistant colonies are only produced when construct integration occurs in frame and downstream of an active promoter. Although this approach has enabled genetargeted colonies to be detected at frequencies of $1-$ $66 \%$ (Table 1), primary cells have a limited lifespan that is further compromised by growth from clonal density. This means few have sufficient vigour to be successfully prepared for NT. Indeed, of 25 targeted colonies identified in experiments targeting the GGTA1 gene in sheep (Table 1), 23 senesced before they could be sufficiently expanded for use in NT (Denning et al., 2001a), thus reducing the effective targeting efficiency by 10-fold (Denning et al., 2001b). Lai et al. (2002) attempted to circumvent this issue in pigs by reducing the overall time in culture and using targeted donor cells immediately on thawing from cryopreservation.

Extended culture and clonal selection of genetically modified cells may also impact on the efficiency of production of viable animals by NT. 'Normal' NT from unmodified donor cells typically has a success rate of between 0 and $4 \%$ of reconstructed embryos developing to become surviving young (Wilmut et al., 2002). The figure is $0-0.5 \%$ in reports using gene-targeted cells (Table 2). In a similar way to unmodified clones that fail to survive, those carrying targeted modifications display a range of anomalies, including defects in the cardiovascular system, liver, kidneys or placenta (De Sousa et al., 2001; Wilmut et al., 2002).

\section{Improving gene targeting in livestock}

As the issues highlighted above hamper the efficient production of gene-targeted livestock, methods are required either that achieve more efficient gene disruption so less cell population doublings are needed and less proliferative capacity is used, or that allow the somatic nucleus to be more efficiently reprogrammed. For successful NT, the donor nucleus must be returned to an embryonic-like state after brief exposure to the oocyte cytoplasm. This remodelling process involves a loss of about $85 \%$ of protein from the donor nuclei concomitant with substantial uptake of proteins from the egg cytoplasm (Gurdon et al., 1979). As a result, the somatic nucleus experiences major changes in epigenetic status, which includes modification of chromatin structure and patterns of methylation. Consequently, major efforts to characterize the remodelling process are underway. In Xenopus egg extract, nucleosomal adenosine triphosphase (ATPase) ISWI, a member of 
Table 2. Rates of developmental progression from gene-targeted primary somatic fibroblasts after cloning by nuclear transfer

\begin{tabular}{|c|c|c|c|c|c|c|}
\hline Target gene & $\begin{array}{c}\text { Reconstructed } \\
\text { embryos }\end{array}$ & Blastocyst & $\begin{array}{c}\text { Fetuses at } \\
\text { day } 60\end{array}$ & Lambs at birth & $\begin{array}{c}\text { Lambs }>6 \\
\text { months of age }\end{array}$ & Reference \\
\hline \multicolumn{7}{|l|}{ Sheep } \\
\hline COL1A1 & 417 & $80(19.2 \%)$ & $20(4.8 \%)$ & $14(3.4 \%)$ & $2(0.5 \%)$ & McCreath et al., 2000 \\
\hline $\operatorname{Pr} P$ & 454 & $47(10.3 \%)$ & $8(1.8 \%)$ & $3(0.7 \%)$ & $0(0 \%)$ & Denning et al., 2001a \\
\hline GGTA1 & 265 & $55(20.7 \%)$ & $7(2.6 \%)$ & $0(0 \%)$ & $0(0 \%)$ & Denning et al., 2001a \\
\hline Target gene & $\begin{array}{c}\text { Reconstructed } \\
\text { embryos }\end{array}$ & $\begin{array}{c}\text { Pregnancies at } \\
\text { day } 25\end{array}$ & $\begin{array}{c}\text { Pregnancies at } \\
\text { day } 45\end{array}$ & Pigs at term & Pigs surviving & Reference \\
\hline \multicolumn{7}{|l|}{ Pig } \\
\hline GGTA1 & 3104 & $28(0.9 \%)$ & $9(0.3 \%)$ & $7(0.2 \%)$ & $4(0.1 \%)$ & Lai et al., 2002 \\
\hline GGTA1 & 2513 & $11(0.4 \%)$ & ND & $5(0.2 \%)$ & $5(0.2 \%)$ & Dai et al., 2002 \\
\hline
\end{tabular}

All percentages in parentheses relate to numbers of reconstructed embryos.

Animal survival is $0-0.5 \%$ using targeted cells as donors for nuclear transfer; using unmodified cells the figure is $0-4 \%$. ND: not determined.

the SWI2/SNF2 superfamily, was identified as a key molecule in chromatin remodelling of Xenopus epithelial cells (Kikyo et al., 2000). Furthermore, Tada et al. (2001) demonstrated reprogramming of the thymocyte genome. Oct 4 is a protein produced during early development. It is not produced in thymocytes, yet a transgene encoding Oct 4-green fluorescent protein engineered into the thymocyte genome was reactivated upon fusion with $\mathrm{mES}$ cells. In addition, fusion also caused the inactive $\mathrm{X}$ chromosome in the thymocyte to adopt some characteristics of an active $\mathrm{X}$ chromosome. Håkelien et al. (2002) analysed the characteristics of human 293T fibroblasts that had been exposed to nuclear and cytoplasmic extract from human T cells. There was evidence of nuclear uptake and assembly of transcription factors, induction of activity of a chromatin remodelling complex, histone acetylation, and activation of lymphoid cell-specific genes. These reports are encouraging in that they indicate that it may be possible to pre-treat somatic cells with reprogramming factors before NT; however, it is likely to be some time before they translate into real improvements in the current low efficiency of viable cloned animals.

One of the significant challenges to be overcome in gene targeting in livestock is the limited lifespan of primary cells in culture. It has been estimated that a total of about 45 population doublings are required to generate targeted cells from fetal tissue using a combination of electroporation, drug selection and highthroughput screening (Clark et al., 2000). Although this appears well within the lifespan of bulk populations of sheep fibroblasts, which can divide up to about 100 times, it is a somewhat artificial comparison because of the heterogeneous nature of the primary culture, and in reality only represents the longevity of the best cells. In fact, from studies in human cells, it has been estimated that cells decline in replicative capacity from the time of explantation and do so in a stochastic manner with a half-life of only about eight doublings (Rubin, 2002). Therefore, as gene targeting protocols in livestock cells use early passage primary cultures, it is not surprising that most colonies fail to proliferate sufficiently to be used in NT and those that do are close to senescence. Increasing the lifespan of the cultured cells would expand the window of opportunity available for gene targeting. For example, primary human fetal foreskin or lung cells can divide an additional ten times if treated with L-carnosine (McFarland and Holliday, 1999). The authors' own research indicates that the superoxide dismutase mimetic, MnTMPyP, can increase longevity in sheep fetal fibroblasts (C. Denning, unpublished). The use of low oxygen tensions $(2 \%)$ rather than standard ambient $(20 \%)$ conditions has been reported to promote the proliferation of pig fetal fibroblasts from single cells, perhaps by reducing the effect of oxidative damage to DNA that may contribute to replicative senescence (Harrison et al., 2002). Finally, when telomeres fall below a critical length, chromosome abnormalities occur more frequently and replicative senescence occurs (Counter et al., 1992). The restoration of telomeres and proliferative capacity in late passage cells to a longer 'juvenile' state by NT (Lanza et al., 2000) has enabled knockout of both GGTA1 alleles in pigs (Phelps et al., 2003). Furthermore, the finding that ectopic expression of human telomerase can maintain telomere length and extend the lifespan of many primary human cells without transformation (Bodnar et al., 1998) may be important for somatic-cell manipulation.

The promoterless gene-targeting strategy is the only method that has been reliably used in primary somatic livestock cells. Although this strategy provides a method to enrich for targeting events, it limits the approach to those genes that are actively transcribed in fibroblasts, currently the only validated type of cell with sufficient longevity to allow selection of gene-targeted cells for NT (Denning et al., 2001b). However, primordial germ 
cells have been isolated from the bovine genital ridge and have displayed a proliferative capacity of up to 85 population doublings (Forsberg et al., 2002). If these cells can support gene-targeting events, they would significantly expand the repertoire of genes open to precise modification. The use of recombinant adenoassociated virus (AAV) has been reported to result in high efficiency (up to $1 \%$ of the cells in culture) targeted insertion of a functional transgene into the hypoxanthine phosphoribosyl transferase (HPRT) and type I collagen (COL1A1) genes in normal human fibroblasts without drug selection or enrichment (Hirata et al., 2002). Although the AAV vectors used in this study were tested only in human cells and were restricted to carrying a maximum of $4 \mathrm{~kb}$ of insert, this approach appears sufficiently promising to warrant further testing in livestock cells.

In specific instances, such as developing ovine models of $\mathrm{CF}$, it may be preferable to reduce the extent of gene function rather than eliminate it per se. In mammalian systems, short regions of double stranded RNA less than 30 bp in length are recruited by the RNAinduced silencing complex, leading to specific cleavage of homologous RNAs in a process known as RNA interference (RNAi) (Hammond et al., 2001). Until recently this approach was confined to short-term, transient assays. However, several groups have developed plasmid-based systems using the RNA polymerase type III promoters $\mathrm{U} 6$ and $\mathrm{H} 1$ to drive expression of short RNAs (shRNAs; Brummelkamp et al., 2002; Lee et al., 2002). Importantly, plasmid and lentiviral vectors expressing shRNAs are effective at long-term silencing of gene expression in $\mathrm{mES}$ cells and transgenic mice (Kunath et al., 2003; Rubinson et al., 2003). Although RNAi is yet to be tested in livestock, the approach may be extended to gene knockdown in these species.

A solution that could potentially address all of the issues raised above would be isolation of ES cells from livestock species. If these cells could be isolated and were to display characteristics similar to $\mathrm{mES}$ cells, such as long lifespan, high efficiencies of homologous recombination and contribution to the germ line in chimaeras, then gene targeting in livestock could be achieved by using ES cells in either the blastocyst injection route or NT, both of which are possible in mice (Fig. 1; Smithies et al., 1985; Rideout et al., 2002). Unfortunately, isolation of livestock ES cells remains a challenging goal.

\section{Human ES cells}

In contrast to livestock, isolation of hES cells has been achieved. Although stem cells have been isolated from other sources, such as cord blood, bone marrow and other adult tissues, this review will focus on hES cells. First derived from the human blastocyst in 1998 (Thomson et al., 1998), hES cells are a unique population (Fig. 2) that meets several key requirements. First, the cells can be propagated indefinitely in vitro in the primitive undifferentiated state. Second, even after long periods of cultivation in vitro the cells can differentiate spontaneously into multiple types of cell, including representatives of all three embryonic germ layers, both in vivo in teratomas after grafting in severe combined immunodeficient (SCID) mice or in vitro under appropriate conditions (Fig. 2). Third, they are stably diploid and karyotypically normal in vitro.

Potentially, human cells with these characteristics offer many opportunities: new approaches to the study of human embryonic development, including birth defects and embryonal tumours; access to human embryonic cells on an unparalleled scale for use in gene expression and genomics; creation of in vitro human disease models for basic research, drug discovery and toxicology; and new delivery systems for gene therapy. A major initiative for hES cells is to direct their differentiation to specific lineages for transplantation, and hence address the current chronic shortage of tissue available for treatment of degenerative diseases. A critical issue, as with most transplants, is graft rejection.

Therapeutic cloning is often suggested as a route to reducing the extent of rejection (Colman and Kind, 2000). In this approach, the patient's own healthy cells, for example from the skin, would be used as donors in NT (Fig. 2). The sole purpose of the blastocysts created from this procedure would be to derive immune compatible hES cells that could be differentiated in vitro to replace the diseased tissue in the patient, for example, dopaminergic neurones in the case of Parkinson's disease. Rideout et al. (2002) demonstrated not only the utility of this approach in mice, but also extended it to include correction of a genetic defect. Somatic nuclei from the tail tip of mice carrying a homozygous mutation in the Rag2 gene, which results in complete absence of B and T cells in the lymphoid organs, were used as donors in NT. After development to the blastocyst stage, ES cells (NT-ES) were isolated and propagated in vitro. Genetic correction of the damaged Rag2 gene was then achieved by gene targeting in the NT-ES cells. These cells were differentiated to a haematopoietic stem cell (HSC) lineage, which restored immune function when transplanted into adult Rag2 mutant mice.

Although this approach represents a major advance, there are a number of issues that remain unresolved. For example, the authors note that the extent of engraftment of the in vitro-derived HSC was low because of rejection by natural killer immune cells, and they speculate that even genetically matched cells derived from therapeutic cloning may face barriers to effective transplantation (Rideout et al., 2002). Furthermore, NT produces only a genomic copy of the donor cell, so peptides derived from mitochondria contributed by the oocyte may also stimulate rejection, although preliminary studies have questioned the validity of 


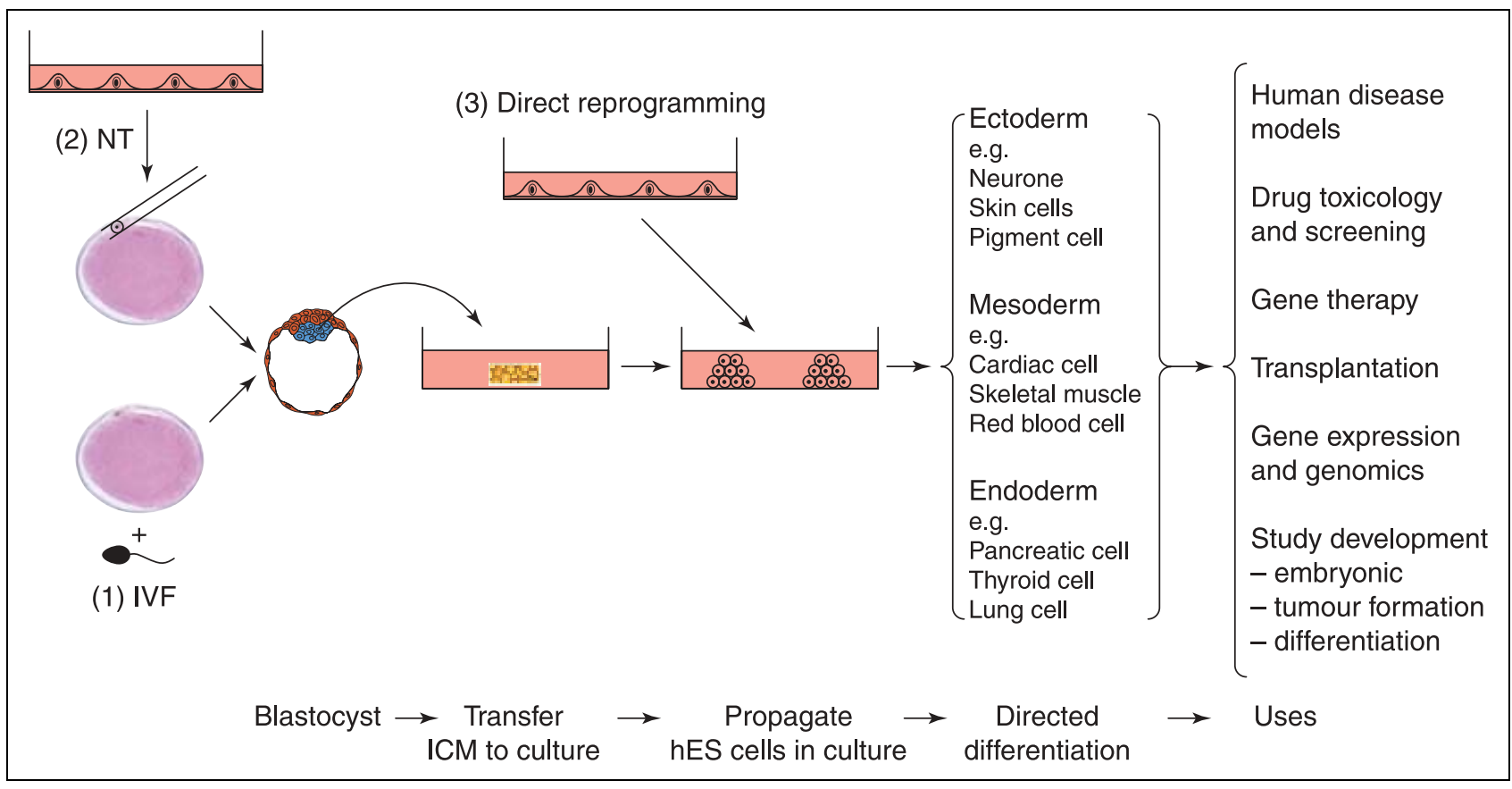

Fig. 2. Isolation and potential uses of human embryonic stem (hES) cells. There are three routes by which hES could be produced: (1) from blastocysts produced by IVF; (2) from blastocysts produced by 'therapeutic cloning' by nuclear transfer (NT) from somatic cells in culture; and (3) by directly reprogramming somatic cells using exogenous factors. All of the approximately 70 hES cells lines established worldwide have been produced from IVF blastocysts; (2) and (3) above have not yet been achieved. The inner cell mass (ICM) is removed from the blastocyst and placed into culture conditions that favour propagation of these embryonic cells. The hES cultures produced can be differentiated in vivo in severe combined immunodeficient mice or in vitro to produce representatives of all three embryonic germ layers. With hES this includes tissues of the fetus and placenta, unlike murine ES cells, which usually contribute to tissues of fetal origin only. There are many potential uses for differentiated derivatives of hES cells, including direct applications in human health, reduction of the number of animals used in biomedical research and as research tools in development and functional genomics.

this concern (Lanza et al., 2002). However, there are significantly more formidable barriers: overcoming the technical challenge of performing the inefficient process of NT with limited supplies of human oocytes, ethical concerns and the financial implications of providing totally characterized, individualized hES cell-based patient therapy and achieving this on a timescale that will benefit a critically ill patient. Whether NT, and hence some of the above issues, can be bypassed by using cellular reprogramming with exogenous factors (see Fig. 2 and previous discussion) is a matter of intense scientific interest. However, even if this approach does become feasible, safety, financial and timescale issues would still remain, raising the question of whether patient-specific therapy is a realistic goal.

Other alternatives must therefore be considered concurrently. A representative bank of hES cells corresponding to a large range of human leukocyte antigen (HLA) types would allow close rather than exact transplant matching. In association with the National Institute for Biological Standards and Control, the Medical Research Council and Biotechnology and Biological Sciences Research Council have established the first international stem-cell bank, which should be in operation by mid-2003 (http://www.nibsc.ac.uk/divisions/cbi/ stemcell.html). Although the size of stem-cell bank required to provide a wide enough range of tissue types to supply the population is not precisely known, extrapolation from a different source, the US National Marrow Donor Program, Minneapolis, may give an indication. In 1995 this programme had access to over 1.9 million HLA-typed donors (Beatty et al., 1995), which matched $70 \%$ of patients, but underrepresentation of racial minorities meant only $34 \%$ of Afro-American patients were matched. By any standards, generating comparable numbers of hES lines would be challenging. Thus, an alternative suggestion is to recruit selected HLA-typed individuals to act as somatic-cell donors for NT to supply specific HLA-typed embryos and reduce the size requirement for a stem-cell bank (Bradley et al., 2002).

Selecting strategies that allow differentiated derivatives of $\mathrm{hES}$ cells to evade the immune system may further condense banking initiatives. Derivation of hES lines from blood group $\mathrm{O}$ embryos and inducing donorspecific tolerance via a chimaeric haematopoetic system may alleviate graft rejection. Bradley et al. (2002) reviewed these topics recently and readers are directed 
to this resource. Alternatively, it may be necessary to 'neutralize' HLA antigens by genetic modification to prevent expression of major histocompatibility class (MHC) I and II molecules (Bradley et al., 2002). This may go some way to providing a universal donor cell line suited to a large number of patients, although it may be associated with its own dangers.

Genetic modification as a tool for providing clinically relevant, functional and safe types of cell will also be important in realising other opportunities for hES cells as therapeutic agents. hES cells have been induced to form embryoid bodies which can differentiate and form types of cell of all three embryonic germ layers (ItskovitzEldor et al., 2000). Differentiation to specific types of cell of developmental (trophoblast; Xu et al., 2002a) and clinical interest has been demonstrated, with the formation of cardiomyocytes (Mummery et al., 2002; $\mathrm{Xu}$ et al., 2002b), insulin-producing cells (Assady et al., 2001), haematopoietic cells (Kaufman et al., 2001; Chadwick et al., 2003), endothelial cells (Levenberg et al., 2002) and cells of neuronal origin (Carpenter et al., 2001; Schuldiner et al., 2001; Zhang et al., 2001). However, most differentiation protocols result in a nonpure, heterogeneous population of cells, containing not only the desired type of cell but also a wide range of other cells, potentially including undifferentiated ES cells. As undifferentiated hES cells form teratomas upon injection into SCID mice (Thomson et al., 1998), there are serious safety concerns about transplantation where there is risk of contamination by undifferentiated cells. Additionally, to ensure a pure and substantial source of the desired types of cell before transplantation, it is likely that the desired differentiated types of cell will need to be purified from the heterogeneous population.

Ectopic expression of transgenes to direct differentiation has been successful in other systems. For example, expression of human bone morphogenetic protein-2 (BMP-2) cDNA in a multipotential murine embryonic mesenchymal cell line is highly effective in directing cells towards a chondrocyte phenotype (Carlberg et al., 2001), whereas expression of HoxB4 in mouse ES cells induces differentiation to haematopoietic stem cells (Kyba et al., 2002). Once the desired types of cell are present in a differentiated culture, they can be purified by expressing selectable genes from a tissue-specific promoter, a technique already applied experimentally to $\mathrm{mES}$ cells to isolate cardiomyocytes at $97 \%$ purity (Muller et al., 2000). Conversely, markers that lead to cell ablation can be used under the control of promoters specific to undifferentiated hES cells in order to address the safety concerns about these potentially tumorigenic cells.

Gene targeting will certainly be required in many of these applications, for example disruption of specific genes involved in $\mathrm{MHC}$ expression. For others, random integration of a transgene may be sufficient. However, as random addition often suffers from mosaicism and unpredictable gene expression (Clark et al., 1994), gene targeting to a known non-essential locus, not subject to repressive influences, would be preferable.

Development of techniques for transgenesis and gene targeting in human ES cells is rapidly progressing. Exogenous DNA has been introduced into hES cells using electroporation (Eiges et al., 2001; Zwaka and Thomson, 2003) and lipofection (Eiges et al., 2001), or viral transduction with lentiviral (Pfeifer et al., 2002) and adenoviral (Smith-Arica et al., in press) vectors. Gene targeting has now been reported in human ES cells (Zwaka and Thomson, 2003). Electroporation of targeting constructs directed to selectable (HPRT1) and non-selectable (Oct 4 or POU5F1) loci resulted in homologous recombination at both, although lipofectionmediated transfection did not. Importantly, targeting frequencies were similar to those associated with mouse ES cells. Targeted cells had a normal, undifferentiated hES morphology and continued to express Oct 4. Although these data are very encouraging, further reports investigating the pluripotentiality and karyotypic stability of gene-targeted hES cells are required. Additionally, both loci targeted by Zwaka and Thomson (2003) are expressed genes and although non-expressed genes are routinely targeted in mouse ES cells (Johnson et al., 1989), this goal has remained elusive in somatic cells so requires investigation in hES cells.

\section{Conclusions}

Targeted genetic modification in mice revolutionized functional genomics in the 1980s. With the development of NT from cultured somatic cells in 1996 and the isolation of hES cells from human blastocysts in 1998, we may be on the verge of another scientific revolution. Both these new fields are currently technically challenging. However, the first insights into the underlying events that occur during NT are emerging. With further development, this will not only be significant to reprogramming of somatic cells from domesticated animals but also in the dedifferentiation of human somatic cells to hES cells, which in turn will be directed to specific differentiated lineages. The role of targeted genetic modification is clear too; it will play a major role in most areas of hES-cell research, from immune compatibility and safety of transplants to directed differentiation and in vitro modelling of human diseases. With sufficient resources, these technologies will make the imagination the limit.

C. Denning is supported by the University of Nottingham and $\mathrm{H}$. Priddle is sponsored by the BBSRC.

\section{References}

Assady S, Maor G, Amit M, Itskovitz-Eldor J, Skorecki KL and Tzukerman M (2001) Insulin production by human embryonic stem cells Diabetes $\mathbf{5 0}$ 1691-1697 
Beatty PG, Kollman C and Howe CW (1995) Unrelated-donor marrow transplants: the experience of the National Marrow Donor Program Clinical Transplantation 271-277

Bodnar AG, Ouellette M, Frolkis M, Holt SE, Chiu CP, Morin GB, Harley CB, Shay JW, Lichtsteiner S and Wright WE (1998) Extension of life-span by introduction of telomerase into normal human cells Science 279 349-352

Bradley JA, Bolton EM and Pedersen RA (2002) Stem-cell medicine encounters the immune system Nature Reviews Immunology 2 859871

Brummelkamp TR, Bernards R and Agami R (2002) A system for stable expression of short interfering RNAs in mammalian cells Science $\mathbf{1 9}$ 550-553

Büeler $H$, Fischer $M$, Lang $Y$, Bluethmann H, Lipp HP, DeArmond SJ, Prusiner SB, Aguet M and Weissmann C (1992) Normal development and behaviour of mice lacking the neuronal cell-surface PrP protein Nature 356 577-582

Burks DJ, de Mora JF, Schubert M, Withers DJ, Myers MG, Towery HH, Altamuro SL, Flint CL and White MF (2000) RS-2 pathways integrate female reproduction and energy homeostasis Nature $\mathbf{4 0 7}$ 377-382

Campbell KHS, McWhir J, Ritchie WA and Wilmut I (1996) Sheep cloned by nuclear transfer from a cultured cell line Nature 380 64-66

Capecchi MR (1989) Altering the genome by homologous recombination Science 244 1288-1292

Carlberg AL, Pucci B, Rallapalli R, Tuan RS and Hall DJ (2001) Efficient chondrogenic differentiation of mesenchymal cells in micromass culture by retroviral gene transfer of BMP-2 Differentiation 67 128-138

Carpenter MK, Inokuma MS, Denham J, Mujtaba T, Chiu CP and Roa MS (2001) Enrichment of neurons and neural precursors from human embryonic stem cells Experimental Neurology 172 383-397

Chadwick K, Wang L, Li L, Menendez P, Murdoch B, Rouleau A and Bhatia M (2003) Cytokines and BMP-4 promote hematopoietic differentiation of human embryonic stem cells Blood pre-published online 17 April, doi: 10.1182/blood-2003-03-0832

Cibelli JB, Stice SL, Golueke PJ, Kane JJ, Jerry J, Blackwell C, Ponce de Leon FA and Robl JM (1998) Transgenic bovine chimeric offspring produced from somatic cell-derived stem-like cells Nature Biotechnology 16642 646

Clark AJ, Bissinger P, Bullock DW, Damak S, Wallace R, Whitelaw CB and Yull F (1994) Chromosomal position effects and the modulation of transgene expression Reproduction, Fertility and Development 6589 598

Clark AJ, Burl S, Denning C and Dickinson P (2000) Gene targeting in livestock: a preview Transgenic Research 9 263-275

Colman A and Kind A (2000) Therapeutic cloning: concepts and practicalities Trends in Biotechnology 18 192-196

Counter CM, Avilion AA, LeFeuvre CE, Stewart NG, Greider CW, Harley CB and Bacchetti S (1992) Telomere shortening associated with chromosome instability is arrested in immortal cells which express telomerase activity EMBO Journal 11 1921-1929

Dai Y, Vaught TD, Boone J et al. (2002) Targeted disruption of the alpha1,3galactosyltransferase gene in cloned pigs Nature Biotechnology 20251 255

Denning C, Burl S, Ainslie A et al. (2001a) Deletion of the alpha(1,3)galactosyl transferase (GGTA1) gene and the prion protein $(\operatorname{Pr} P)$ gene in sheep Nature Biotechnology 19 559-562

Denning C, Dickinson P, Burl S, Wylie D, Fletcher J and Clark AJ (2001b) Gene targeting in primary fetal fibroblasts from sheep and pig Cloning and Stem Cells 3 221-231

De Sousa PA, King T, Harkness L, Young LE, Walker SK and Wilmut I (2001) Evaluation of gestational deficiencies in cloned sheep fetuses and placentae Biology of Reproduction 65 23-30

Eiges R, Schuldiner M, Drukker M, Yanuka O, Itskovitz-Eldor J and Benvenisty $\mathbf{N}$ (2001) Establishment of human embryonic stem celltransfected clones carrying a marker for undifferentiated cells Current Biology 11 514-518

Evans MJ and Kaufman MH (1981) Establishment in culture of pluripotential cells from mouse embryos Nature 292 154-156
Fan J, Challah $\mathbf{M}$ and Watanabe T (1999) Transgenic rabbit models for biomedical research: current status, basic methods and future perspectives Pathology International 49 583-594

Forsberg EJ, Strelchenko NS, Augenstein ML et al. (2002) Production of cloned cattle from in vitro systems Biology of Reproduction 67 327-333

Galili U, Macher BA, Buehler J and Shohet SB (1985) Human natural antialpha-galactosyl IgG. II. The specific recognition of alpha (1-3)-linked galactose residues Journal of Experimental Medicine 162 573-582

Gurdon JB, Laskey RA, De Robertis EM and Partington GA (1979) Reprogramming of transplanted nuclei in amphibia International Reviews of Cytology Supplement 9 161-178

*Håkelien AM, Landsverk HB, Robl JM, Skalhegg BS and Collas P (2002) Reprogramming fibroblasts to express T-cell functions using cell extracts Nature Biotechnology 20 460-466

Hammond SM, Caudy AA and Hannon GJ (2001) Post-transcriptional gene silencing by double-stranded RNA Nature Reviews Genetics 2 110-119

Harris A (1997) Towards an ovine model of cystic fibrosis Human Molecular Genetics 6 2191-2193

Harrison SJ, Guidolin A, Faast R, Crocker LA, Giannakis C, D'Apice AJ Nottle MB and Lyons I (2002) Efficient generation of alpha(1,3) galactosyltransferase knockout porcine fetal fibroblasts for nuclear transfer Transgenic Research 11 143-150

Heasman L, Clarke L, Firth K, Stephenson T and Symonds ME (1998) Influence of restricted maternal nutrition in early to mid gestation on placental and fetal development at term in sheep Pediatric Research 44 546-551

Hirata R, Chamberlain J, Dong R and Russell DW (2002) Targeted transgene insertion into human chromosomes by adeno-associated virus vectors Nature Biotechnology 20 735-738

Itskovitz-Eldor J, Schuldiner M, Karsenti D, Eden A, Yanuka O, Amit M, Soreq $\mathbf{H}$ and Benvenisty N (2000) Differentiation of human embryonic stem cells into embryoid bodies comprising the three embryonic germ layers Molecular Medicine 6 88-95

Johnson RS, Sheng M, Greenberg ME, Kolodner RD, Papaioannou VE and Spiegelman BM (1989) Targeting of nonexpressed genes in embryonic stem cells via homologous recombination Science 245 1234-1236

Kaufman DS, Hanson ET, Lewis RL, Auerbach R and Thomson JA (2001) Hematopoietic colony-forming cells derived from human embryonic stem cells Proceedings National Academy of Sciences USA 9810716 10721

Kikyo N, Wade PA, Guschin D, Ge H and Wolffe AP (2000) Active remodeling of somatic nuclei in egg cytoplasm by the nucleosomal ATPase ISWI Science 289 2360-2362

Kunath T, Gish G, Lickert H, Jones N, Pawson T and Rossant J (2003) Transgenic RNA interference in ES cell-derived embryos recapitulates a genetic null phenotype Nature Biotechnology pre-published online 7 April, doi: 10.1038/nbt813

Kyba M, Perlingeiro RC and Daley GQ (2002) HoxB4 confers definitive lymphoid-myeloid engraftment potential on embryonic stem cell and yolk sac hematopoietic progenitors Cell 109 29-37

Lai L, Kolber-Simonds D, Park KW et al. (2002) Production of alpha-1,3galactosyltransferase knockout pigs by nuclear transfer cloning Science 295 1089-1092

Lanza RP, Cibelli JB, Blackwell C et al. (2000) Extension of cell life-span and telomere length in animals cloned from senescent somatic cells Science 288 665-669

Lanza RP, Chung HY, Yoo JJ et al. (2002) Generation of histocompatible tissues using nuclear transplantation Nature Biotechnology 20 689-696

Lee NS, Dohjima T, Bauer G, Li H, Li MJ, Ehsani A, Salvaterra P and Rossi J (2002) Expression of small interfering RNAs targeted against HIV-1 rev transcripts in human cells Nature Biotechnology 20 500-505

Levenberg, S, Golub JS, Amit M, Itskovitz-Eldor J and Langer R (2002) Endothelial cells derived from human embryonic stem cells Proceedings National Academy of Sciences USA 99 4391-4396

McCreath KJ, Howcroft J, Campbell KH, Colman A, Schnieke AE and Kind AJ (2000) Production of gene-targeted sheep by nuclear transfer from cultured somatic cells Nature 405 1066-1069 
McFarland GA and Holliday R (1999) Further evidence for the rejuvenating effects of the dipeptide L-carnosine on cultured human diploid fibroblasts Experimental Gerontology 34 35-45

Martin GR (1981) Isolation of a pluripotent cell line from early mouse embryos cultured in medium conditioned by teratocarcinoma stem cells Proceedings National Academy of Sciences USA 78 7634-7638

Muller M, Fleischmann BK, Selbert S et al. (2000) Selection of ventricularlike cardiomyocytes from ES cells in vitro. FASEB Journal 142540 2548

Mummery C, Ward D, van den Brink CE, Bird SD, Doevendans PA, Opthof $T$, Brutel de la Riviere $A$, Tertoolen $L$ and van der Heyden $M$ (2002) Cardiomyocyte differentiation of mouse and human embryonic stem cells Journal of Anatomy $200233-242$

Okkenhaug K, Bilancio A, Farjot G et al. (2002) Impaired B and $\mathrm{T}$ cell antigen receptor signaling in p110delta PI 3-kinase mutant mice Science 297 1031-1034 (see supporting online material, doi: 10.1126/science.1073560)

Pfeifer A, Ikawa M, Dayn Y and Verma IM (2002) Transgenesis by lentiviral vectors: lack of gene silencing in mammalian embryonic stem cells and preimplantation embryos Proceedings National Academy of Sciences USA 99 2140-2145

*Phelps CJ, Koike C, Vaught TD et al. (2003) Production of alpha 1,3galactosyltransferase-deficient pigs Science 299 411-414

Piedrahita JA, Moore K, Oetama B et al. (1998) Generation of transgenic porcine chimeras using primordial germ cell-derived colonies Biology of Reproduction 58 1321-1329

Prather RS, Barnes FL, Sims MM, Robl JM, Eyestone WH and First NL (1987) Nuclear transplantation in the bovine embryo: assessment of donor nuclei and recipient oocyte Biology of Reproduction 37 859-866

Rideout WM 3rd, Hochedlinger K, Kyba M, Daley GQ and Jaenisch R (2002) Correction of a genetic defect by nuclear transplantation and combined cell and gene therapy Cell 109 17-27

Rubin H (2002) The disparity between human cell senescence in vitro and lifelong replication in vivo. Nature Biotechnology 20 675-681

*Rubinson DA, Dillon CP, Kwiatkowski AV et al. (2003) A lentivirus-based system to functionally silence genes in primary mammalian cells, stem cells and transgenic mice by RNA interference Nature Genetics 33 401406
Schnieke AE, Kind AJ, Ritchie WA, Mycock K, Scott AR, Ritchie M, Wilmut I, Colman A and Campbell KHS (1997) Human factor IX transgenic sheep produced by transfer of nuclei from transfected fetal fibroblasts Science 278 2130-2133

Schuldiner M, Eiges R, Eden A, Yanuka O, Itskovitz-Eldor J, Goldstein RS and Benvenisty $\mathbf{N}$ (2001) Induced neuronal differentiation of human embryonic stem cells Brain Research 913 201-205

Smith-Arica JR, Thomson AJ, Ansell R, Chiorini J, Davidson B and McWhir J (2003) Infection efficiency of human and mouse embryonic stem cells using adenoviral and adeno-associated viral vectors Cloning and Stem Cells 5 51-62

Smithies O, Gregg RG, Boggs SS, Koralewski MA and Kucherlapati RS (1985) Insertion of DNA sequences into the human chromosomal betaglobin locus by homologous recombination Nature 317 230-234

Tada M, Takahama Y, Abe K, Nakatsuji N and Tada T (2001) Nuclear reprogramming of somatic cells by in vitro hybridization with ES cells Current Biology 11 1553-1558

Templeton NS, Roberts DD and Safer B (1997) Efficient gene targeting in mouse embryonic stem cells Gene Therapy 4 700-709

*Thomson JA, Itskovitz-Eldor J, Shapiro SS, Waknitz MA, Swiergiel JJ, Marshall VS and Jones JM (1998) Embryonic stem cell lines derived from human blastocysts Science 282 1145-1147

Wilmut I and Peterson LA (2002) Somatic Cell Nuclear Transfer (cloning) Efficiency http://www.roslin.ac.uk/public/webtablesGR.pdf

Wilmut I, Beaujean N, De Sousa PA, Dinnyes A, King TJ, Paterson LA, Wells DN and Young LE (2002) Somatic cell nuclear transfer Nature 419 583-587

Xu R, Chen X, Li D, Rui L, Addicks G, Glennon C, Zwaka T and Thomson J (2002a) BMP4 initiates human embryonic stem cell differentiation to trophoblast Nature Biotechnology 20 1261-1264

Xu C, Police S, Rao N and Carpenter MK (2002b) Characterization and enrichment of cardiomyocytes derived from human embryonic stem cells Circulation Research 91 501-508

Zhang SC, Wernig M, Duncan ID, Brustle O and Thomson JA (2001) In vitro differentiation of transplantable neural precursors from human embryonic stem cells Nature Biotechnology 19 1129-1133

*Zwaka TP and Thomson JA (2003) Homologous recombination in human embryonic stem cells Nature Biotechnology 21 319-321 